\title{
A mulher nos ensaios de Ernesto Sabato'
}

\author{
Margarete Hülsendeger (PUCRS)* \\ http://orcid.org/0000-0002-4991-9769
}

\section{Resumo:}

A escrita de ensaios é vista como um processo de criação artística capaz de, mesmo que não seja seu fim exclusivo, interpretar as realidades sociopolíticas e econômicas. Na América hispânica, importantes escritores se dedicaram a esse gênero, entre eles o argentino Ernesto Sabato (1911-2011). Seus ensaios apresentam uma visão particular sobre diferentes assuntos, desde fatos relacionados à literatura até aqueles que são um reflexo da sua forma de ver o mundo. Entre os temas que aparecem de maneira recorrente está a sua aversão a tudo que esteja ligado ao pensamento científico. Como sua visão negativa da ciência influencia até mesmo questões relacionadas ao comportamento de homens e mulheres, neste artigo foram analisadas as possíveis razões por trás da insistência de Sabato em afirmar que as mulheres não conseguem compreender as leis científicas, não têm interesse pela abstração e, portanto, não têm aptidão para serem filósofas ou matemáticas. Para fundamentar essa análise utilizaram-se como referência diversos ensaios escritos por Sabato, dando-se especial atenção a Heterodoxia (1953).

Palavras-chave: Ernesto Sabato; Mulher; Ensaio.

\section{Abstract:}

\section{Women in the essays of Ernesto Sabato}

Essay writing is seen as a process of artistic creation capable of, even if it is not its exclusive purpose, interpret socio-political and economic realities. In hispanic America, important writers dedicated themselves to this genre, including Argentinian Ernesto Sabato (1911-2011). His essays present a particular view on different subjects, from facts related to literature to those that are a reflection of his way of seeing the world. Among the themes that appear on a recurring basis is his aversion to everything connected with scientific thought. As his negative view of science influences even issues related to the behavior of men and women, this article analyzed the possible

1 Este texto é um recorte da tese de doutorado (HÜLSENDEGER, 2020) em Teoria da Literatura cujo objetivo geral foi investigar como a aversão ao espírito científico, manifestada por Ernesto Sabato em seus ensaios, transparece na sua obra ficcional. 0 trabalho foi realizado com apoio da Coordenação de Aperfeiçoamento de Pessoal de Nível Superior - Brasil (CAPES) - Código de Financiamento 001 [This study was financed in part by the Coordenação de Aperfeiçoamento de Pessoal de Nivel Superior - Brasil (CAPES) - Finance Code 00].

* Doutora em Teoria da Literatura (PUCRS). Mestra em Teoria da Literatura (PUCRS). Mestra em Educação em Ciências e Matemática (PUCRS). E-mail: margacenteno@gmail.com 
reasons behind Sabato's insistence that women cannot understand scientific laws, have no interest in abstraction and, therefore, they are not apt to be philosophers or mathematicians. To base this analysis, several essays written by Sabato were used as reference, with special attention to Heterodoxia (1953).

Keywords: Ernesto Sabato; Woman; Essay.

\section{Introdução}

O ensaio, devido ao seu caráter indefinido, tem a capacidade de sintetizar as múltiplas manifestações textuais das quais procede. Desse modo, ele não pode ser encarado como um simples exercício de interpretação ou apenas como um processo de comunicação de convicções. Para Liliana Weinberg, o ensaio é uma "poética da interpretação, uma configuração da prosa que nos remete a sua própria especificidade, a sua própria opacidade, a sua própria capacidade de exemplificar esse mesmo processo de interpretação" (WEINBERG, 2007a, p. 120, tradução nossa) $)^{2}$.Como resultado, atualmente, o ensaio pode ser visto como um "arquipélago complexo" em permanente reconfiguração devido a uma "inter-relacionalidade aberta e dinâmica", onde o lugar da enunciação recebe "particular atenção, assim como o próprio ato da escrita possui particular importância" (WEINBERG, 2017, p. 542).

Na América espanhola, desde o século XIX a forma ensaística já se fazia presente e a passagem do tempo não reduziu sua vitalidade e importância. No entanto, o ensaio passou por uma série de transformações que respondiam aos desafios do momento: "as novas demandas temáticas e formais, as transformações na família da prosa de ideias, assim como nos novos fenômenos

2 "[...] poética de la interpretación, una configuración de la prosa que nos remite a su propia especificidad, a su propia opacidad, a su propia capacidad de ejemplificar ese mismo proceso de interpretación". de autoria, leitura e edição experimentados no campo das letras (WEINBERG, 2007b, p. 111, tradução nossa) ${ }^{3}$. É assim, por exemplo, com Mario Vargas Llosa, Ricardo Piglia (1941-2017), Carlos Fuentes (1928-2012) e Juan José Saer (1937-2005). Podendo-se acrescentar a essa lista de importantes ensaístas hispano-americanos o escritor argentino Ernesto Sabato ${ }^{4}$ (1911-2011).

Em um exame mais detalhado da ensaística sabatiana é possível encontrar diferentes pontos de vista sobre os mais diversos temas: desde os relacionados diretamente a literatura até aqueles que são um reflexo de sua concepção de mundo. Entre as ideias que aparecem de forma recorrente está a sua aversão a tudo que esteja ligado ao pensamento científico. Nesse sentido, Sabato destacava o aumento da abstração da ciência como uma das razões do distanciamento do homem de seus problemas mais urgentes. Esse afastamento do concreto, do real, levaria a uma sensação de não perten-

3 " [...] a las nuevas demandas temáticas y formales, a las transformaciones en la familia de la prosa de ideas, así como también en los nuevos fenómenos de autoría, lectura y edición que vive el campo de las letras".

4 Optou-se por utilizar a grafia de Sabato, sem acento, tendo como base as informações presentes na biografia escrita por Julia Constenla que explica tratar-se de um nome originário da Itália, mais especificamente da Calábria (CONSTENLA, 2011). Como muitas obras (brasileiras e argentinas) apresentam o nome do autor com acento, nesses casos, escolheu-se respeitar as informações da ficha catalográfica. 
cimento causa de muitos dos tormentos que atingem o homem moderno. Por isso, de acordo com Sabato, a ciência "foi evoluindo rapidamente para a abstração, aumentando correlativamente sua escuridão e ganhando o prestígio que as pessoas comuns concediam à magia, teologia e metafíca" (SABATO, 2011a, p. 78, tradução nossa) ${ }^{5}$.

Essa visão negativa da ciência influenciava seu pensamento de tal forma que até mesmo questões relacionadas ao comportamento de homens e mulheres eram julgadas a partir dessa perspectiva. Assim, Sabato defendia que enquanto o homem estava sujeito aos efeitos danosos provocados pela ciência, a mulher era imune a eles. A imunidade feminina teria como causa o fato de a mulher ao preocupar-se com "coisas concretas" afastava-se "naturalmente" de áreas do conhecimento relacionadas com o pensamento abstrato (matemática, filosofia, física ou química). A defesa dessas ideias aparece em vários ensaios, mas tem mais força em Heterodoxia, livro publicado em 1953. Podese conjecturar que Sabato ao ser criado em uma sociedade patriarcal, onde as mulheres permaneciam confinadas aos papéis subalternos da logística de uma casa, simplesmente tenha reproduzido esses conceitos vendo -os como naturais. Contudo, Sabato não era um homem comum. Além de escritor, havia sido físico chegando a trabalhar em um laboratório de pesquisas, internacionalmente conhecido, cuja diretora era uma mulher, a química e Prêmio Nobel, Irène Juliot-Curie (1897-1956). Além disso, nas suas ficções aparecem mulheres em posições centrais María Iribarne (El túnel) e Alejandra Olmos (Sobre heroes y tumbas), em especial - que

5 " [...] fue evolucionando rapidamente hacia la abstracción, aumentando en forma correlativa su oscuridad y ganando el prestigio que antes el vulgo concedía a la magia, a la teología y a la metafísica". se mostram independentes e complexas e, portanto, na contramão das características femininas destacadas por Sabato.

Por esse motivo, neste artigo são examinadas as possíveis razões por trás da insistência de Sabato em afirmar que as mulheres não conseguem compreender as leis científicas, não têm interesse pela abstração e, como consequência, não têm capacidade para serem filósofas ou matemáticas. Para fundamentar essa análise foram utilizados como referência diversos ensaios escritos por Sabato, dando-se especial atenção a $\mathrm{He}$ terodoxia (1953), obra na qual aparece com mais clareza suas ideias sobre a posição da mulher na sociedade, em particular, no campo científico.

\section{Ernesto Sabato, o franco atirador}

Sabato foi descrito por uma de suas biógrafas, María Angélica Correa, da seguinte maneira: "É um homem magro, nervoso, que se move constantemente ao falar e sobre quem qualquer terno parece enrugado" (CORREA, 1971, p. 9, tradução nossa) ${ }^{6}$. Ela ainda comenta que por trás de toda a sua combatividade se encontra "um homem inseguro e muito vulnerável, sempre descontente consigo mesmo" (CORREA, 1971, p. 11 , tradução nossa) ${ }^{7}$. Para corroborar essa impressão, em entrevista a Günter Lorenz, o próprio Sabato se definiu como sendo um homem complicado, "propenso ao extremismo de sentimentos", deixando-se, muitas vezes, levar por "ações demasiado brutais, quase histéricas" (LORENZ, 1973, p. 42).

Por conta desse temperamento, Sabato quando tomava uma decisão não costumava voltar atrás. Foi o que ocorreu quando de-

6 "Es un hombre flaco, puro nervio, que se mueve constantemente al hablar, y sobre quien cualquier traje parece arrugado".

7 "[...] un hombre inseguro y muy vulnerable, perpetuamente descontento de sí mismo". 
cidiu abandonar seu cargo de professor de física na Universidade de La Plata para se dedicar à literatura. 0 conflito que o teria levado a romper com a ciência, assemelhavase ao movimento de uma ponte estendendose entre duas enormes montanhas, fazendo com que ele se sentisse, em alguns momentos, "tonto e sem saber o que estava fazendo e, em outros, com a alegria imparável que acompanha o nascimento de toda grande paixão" (SABATO, 2011b, p. 66-67, tradução nossa $)^{8}$. Um doutor em física que passou a pregar a impossibilidade de se estabelecer qualquer tipo de diálogo entre a ciência e a literatura. Segundo Sabato, enquanto a ciência aspirava unicamente a objetividade, a literatura era, ao mesmo tempo, objetiva e subjetiva, constituindo uma realidade mais integral que a científica

A partir do momento que começa a escrever, Sabato assume-se como um escritor preocupado com a terrível crise do homem moderno e, por isso, sente-se na obrigação de expressar suas ideias dizendo que elas são o resultado de suas próprias experiências pessoais. Ele considerava-se um franco-atirador solitário tendo por principal alvo a dependência da sociedade moderna para com os avanços propiciados pela ciência, avanços que esqueciam o "homem concreto" (h) e suas necessidades, focando sua atenção no "homem abstrato" (H) que ele menosprezava. Assim, quando destacava os problemas do universo científico, defendendo a ideia de que apenas nas artes e na literatura o homem poderia atingir todo o seu potencial, Sabato estava dizendo ao seu leitor que qualquer compromisso que ele pudesse ter tido com a ciência havia definitivamente se encerrado.

8 "[...] mareado y sin saber lo que estaba haciendo, y en otros, en cambio, con el gozo irrefrenable que acompaña al nacimiento de toda gran pasión"
Esse encerramento, no entanto, nunca foi completo. Na verdade, em seus ensaios ainda é possível perceber a presença de ideias sobre o pensamento científico das quais ele não conseguiu se desvincular. Ideias que o levam a escrever, por exemplo, que o homem "tende ao mundo da abstração, das ideias puras, da razão e da lógica" enquanto, a mulher "se move melhor no mundo concreto, das ideias puras, do irracional, do intuitivo" (SABATO, 2011a, p. 14, tradução nossa) ${ }^{9}$. Essa relação entre a aptidão para o abstrato (marca do pensamento científico) e o gênero foi a maneira encontrada por Sabato para demonstrar que enquanto os homens estão presos a lógica e ao rigor científico, as mulheres estão mais abertas para compreender as profundezas da natureza humana.

0 grande problema é que ao dizer-se um admirador das mulheres, seu discurso acaba se tornando contraditório. Ao mesmo tempo que descreve as qualidades femininas - altruísmo, sentido do misterioso e capacidade de sacrifício - lança-se contra o pensamento feminista. De acordo com Sabato, no século XIX não só se defendeu a ideia de que o homem que viajava de trem era superior ao que andava a cavalo, como passou-se a apregoar a doutrina "mais inesperada de todos os tempos; a ideia da identidade dos sexos" (SABATO, 2011a, p. 9, tradução nossa) ${ }^{10}$. Seu discurso contra o feminismo fica ainda mais radical quando fala das mulheres cultas. Segundo ele, elas não teriam compreendido que defender as teses feministas significava colocá-las "em um terreno desfavorável: como se um submarino, incomodado com o prestígio da aviação, fingisse ser tão bom

9 "[...] tiende al mundo de la abstracción, de las ideas puras, de la razón y de la lógica" [...] "se mueve mejor en el mundo de lo concreto, de las ideas impuras, de lo irracional, de lo intuitivo".

10 "[...] más inesperada de todos los tiempos, en la idea de la identidad de los sexos". 
quanto um avião... no ar" (SABATO, 2011a, p. 10 , tradução nossa) ${ }^{11}$.

0 feminismo, com seus conceitos de emancipação e direitos iguais, irritava Sabato. A defesa dessas ideias expressava um rompimento com o modelo de mulher sustentado por uma sociedade conservadora e patriarcal. Para ilustrar esse pensamento, ele lançava mão de exemplos que eram, muitas vezes, um pouco forçados:

Louise Coleta, a mulher pela qual Flaubert se desesperou, teve como amantes Victor Cousin, Victor Hujo, Alfred de Musset e Aldred de Vigny que, casualmente, ganhou, por quatro vezes, o prêmio de poesia que anualmente ofereciam esses quatro cavalheiros. No entanto, escrevia tão mal que até o próprio Flaubert a tinha avisado" (SABATO, 2011a, p. 34, tradução nossa) ${ }^{12}$.

Blas Matamoro explica que Sabato obedecia a um código sexual patriarcal, defendendo-o como natural, onde o homem "entra na fêmea como o conquistador em uma terra inimiga. Possui, domina" (MATAMORO, 1990, p. 220, tradução nossa) ${ }^{13}$. Esse código teria sido, ainda segundo Matamoro, baseado nas ideias do filósofo austríaco Otto Weininger (1880-1903) que em seu livro Sex and Character (1903) defende, entre outros pontos, o caráter ativo, produtivo, consciente e moral do homem em contraposição ao caráter passivo, improdutivo, inconsciente e amoral da mulher. Ademais, para Weininger, a emancipação feminina só teria sentido

11 “[...] en un terreno desfavorable: como si un submarino, molesto por el prestigio de la aviación, pretendiese ser tan bueno como avión... en el aire"

12 "Louise Colet, la mujer por la que Flaubert se desesperó, tuvo por amantes a Victor Cousin, Víctor Hugo, Alfred de Musset y Alfred de Vigny. Y, qué causalidad, obtuvo por cuatro veces el premio de poesía que anualmente otorgaban esos cuatro caballeros. No obstante escribir tan mal que hasta el propio Flaubert lo advertía".

13 "[...] entra en la hembra como el conquistador en una tierra enemiga. Posee, domina". para o que ele chamou de "mulher masculina" (as lésbicas) e que a vida da mulher estaria consumida pela função sexual, tanto como ato (a prostituta) quanto como produto (a mãe) (WEININGER, 2005).

Estranhamente, ao adotar essas ideias, Sabato parece esquecer nomes como o de Irène Curie (1897-1956), Prêmio Nobel de Química de 1935 e fundadora do laboratório no qual trabalhou em 1937, bem como de María Zambrano (1904-1991) e Hannah Arendt (1906-1975), duas mulheres filósofas, suas contemporâneas. Há, portanto, uma clara ambivalência em seu discurso. De um lado temos um Sabato capaz de exaltar as virtudes femininas, enquanto de outro ele as ataca ferozmente, demonstrando uma misoginia difícil de compreender. A seguir apresentamos como essas contradições são construídas e quais os recursos utilizados pelo escritor para fundamentá-las.

\section{As mulheres de Sabato}

Em España en los diarios de mi vejez (2004), último livro publicado por Sabato, ele faz uma homenagem a sua mãe, definindo-a como uma daquelas "mulheres de antes, das que hoje não existem" (SABATO, 2004, p. 56, tradução nossa) ${ }^{14}$. 0 que ele quis dizer com isso? Talvez que sua mãe fazia parte do grupo de mulheres delicadas, silenciosas, belas, românticas, inatingíveis, frágeis e modestas que, para ele, deixaram de existir. Uma definição que lembra matéria publicada por uma revista, de grande circulação, em 2016, quando na capa estampou a foto da esposa do presidente brasileiro acompanhada da frase, "Bela, recatada e do lar"15, um título que, na época, ganhou a reprovação da

14 "[...] mujeres de antes, de las que ya no las hay".

15 Disponível em: https://veja.abril.com.br/brasil/ marcela-temer-bela-recatada-e-do-lar/. Acesso em: 28 jul 2020. 
maioria das brasileiras. No entanto, quando escreveu essas palavras em 2004, Sabato admitiu que sua opinião poderia aborrecer as mulheres por que veriam "no que digo uma atitude machista, querendo dizer algo que as prejudica, desvalorizando sua capacidade e as oportunidades que têm direito. Não sei, quem sabe tenham razão, mas creio que não, eu falo com amor por elas" (SABAT0, 2004, p. 56, tradução nossa) ${ }^{16}$.

Esse reconhecimento (mesmo que parcial), 70 anos antes, quando escreveu $\mathrm{He}$ terodoxia (1953), estava fora de cogitação. Nessa obra, Sabato expôs o que se poderia chamar de sua "teoria sobre os sexos", preocupando-se não só em estabelecer as diferenças entre homens e mulheres, mas advogando contra as teorias feministas. Na sua apresentação para edição em português, publicada em 1993, Janer Cristaldo escreve que "Sábato investiga as raízes da conspiração", ou seja, o novo "dogma" no qual se "tornar-se homem ou mulher era questão de opção cultural, não de constituição física ou psicológica" (CRISTALDO In SÁBATO, 1993, p. 8). Cristaldo, quem sabe, tentando justificar-se diante do público leitor feminino, chega a dizer que Sabato é um "daqueles homens conservadores à antiga, que ainda gosta de mulheres, preferentemente das lindas, femininas e inteligentes". Uma afirmativa também muito semelhante àquela feita pela revista em 2016.

Sabato constrói seus argumentos sobre os sexos a partir de antinomias: o homem é lógico, a mulher não é; o homem é insensato, a mulher é sensata; o homem é dado a fantasias, a mulher é realista e conservadora. Essas oposições colocam em evidência a ideia

16 "[...] en lo que digo una actitud machista, queriendo decir algo que las perjudica, desvalorizando su capacidad y las oportunidades a las que tienen derecho. No sé, quizá tengan razón, pero creo que no, lo digo con amor hacia ellas". de que na mulher há um saber inato para o altruísmo, provocado por sua capacidade de sacrificar-se pelos filhos e pelos homens que estão ao seu cuidado. Os homens, ao contrário, por não terem esse sentido de sacrifício desenvolvido "matam-se por ideias e isso é quase um ato de loucura" (SABATO, 2011a, p. 92, tradução nossa $)^{17}$. Uma loucura da qual as mulheres estão supostamente protegidas porque se preocupam com "coisas concretas" ou, no máximo, com ideias relacionadas, de alguma maneira, com essas "coisas concretas". Desse modo, o desejo de conhecimento da mulher dirige-se sempre "às coisas mesmas e não às causas remotas às quais obedecem; ela não está interessada em contar as batidas de um coração que sofre, mas saber porque sofre" (SABATO, 2011a, p. 12, tradução nossa) ${ }^{18}$. É tomando como ponto de partida essa diferença de interesses, que Sabato procura demonstrar o suposto desprezo da mulher pelo pensamento abstrato e, consequentemente, pela filosofia, a matemática e as ciências de um modo geral.

Sabato é taxativo ao dizer que, para as mulheres, as ideias puras não existem ou não têm sentido e se elas as toleram ou admiram é devido a sua "ternura maternal pelos seres (homens) que ela ama e que é capaz de admirar mesmo em seus atos de insanidade" (SABAT0, 2011a, p. 56, tradução nossa $)^{19}$. Essa natureza maternal, traço predominante na psicologia feminina, é o que determinaria as características de seu mundo (concreto, pequeno e pessoal). Um

17 "[...] se matan por ideas, y eso es casi un acto de locura".

18 "[...] a las cosas mismas y no a las remotas causas a que obedecen; no la interesa contar las pulsaciones de un corazón que sufre, sino el saber por qué sufre".

19 "[...] maternal ternura por los seres (los hombres) que quiere y que es capaz de admirar hasta en sus actos de demencia". 
mundo onde não há espaço para a matemática ou a física, pois, ele estaria configurado para o mundo masculino, um mundo de poder e abstração. Assim, enquanto a mulher fecha-se em casa e limita-se às experiências possíveis dentro da sua realidade, o homem lança-se em busca de aventuras, de conquistas de outros universos, tanto físicos como espirituais. Esse seria, então, o motivo, segundo Sabato, pelo qual a mulher "nunca produziu filosofia, porque o que é mais insano do que um sistema filosófico?" (SABAT0, 2011a, p. 14, tradução nossa) ${ }^{20}$. Uma afirmativa claramente discutível quando se pensa no número significativo de mulheres, suas contemporâneas, que fizeram contribuições importantes para a filosofia: Simone Weill (1909-1943), Simone de Beauvoir (1908-1986), Hannah Arendt (1906-1975), María Zambrano (1904-1991), Ayn Rand (1905-1982), entre outras.

Ele insiste em dizer que essa inaptidão para o abstrato pode ser observada em diferentes civilizações, argumentando que existem "testemunhos valiosos que provam não a incapacidade das mulheres para abstração, mas sua indiferença e até mesmo seu desgosto" (SABATO, 2011a, p. 11, tradução nossa) ${ }^{21}$. E quais seriam esses testemunhos? Obviamente, nenhum dos citados no parágrafo anterior.

Sabato busca, então, mulheres que, de alguma forma, compactuam ou reforçam suas ideias. E ele as encontra. Para explicar as diferenças biológicas entre o homem e a mulher e para criticar o feminismo, ele cita a italiana Gina Lombroso (1872-1944); para demonstrar o quanto as mulheres são dominadas pelas suas emoções, sendo irra-

20 "[...] no ha producido nunca filosofía, porque, ¿qué más descabellado que un sistema filosófico?".

21 "[...] testimonios valiosos que prueban no la incapacidad de la mujer para la abstracción sino su indiferencia y hasta su repugnancia". cionais e ilógicas, ele aponta a matemática russa Sofia Kowalevskaya (1850-1891). Uma pesquisa sobre essas duas mulheres nos permite perceber não só o porquê dessas escolhas, mas também algumas das contradições que as acompanham.

Gina Lombroso foi autora de obras polêmicas como Reflexões sobre a vida. A alma da mulher. Livro I: A trágica posição da muIher (1917), Reflexões sobre a vida. A alma da mulher. Livro II: Consequências do altruísmo (1918) e Eu sou, prós e contras. Reflexões sobre a votação para as mulheres (1919). Nesses livros ela expõe suas ideias sobre a condição da mulher e faz fortes críticas ao feminismo. A princípio pode-se acreditar que Sabato a escolhe, justamente, por defender uma posição submissa da mulher diante do homem. Em seguida percebe-se tratar de um pensamento simplista, pois Gina Lombroso não foi um modelo de submissão, mas uma mulher complexa, inteligente e o mais surpreendente, uma defensora (a seu modo) dos direitos femininos. A pesquisadora italiana Marina Calloni, da Universidade de Milão, a partir de seus estudos sobre Lombroso, explica que ela era uma mulher em constante conflito entre seu trabalho científico e sua defesa do papel tradicional das mulheres. Segundo Calloni, a fidelidade aos ideais do pai, o antropólogo e psiquiatra Cesare Lombroso (1835-1909) - defensor de uma reinterpretação dos ditames positivistas em relação aos sexos -, foi a causa de muitas das contradições de Gina como mulher, cientista e ativista (CALLONI, 2016).

Lombroso queria reiterar a perspectiva positivista de seu pai sobre as diferenças básicas entre os sexos, admitindo um processo evolutivo das espécies que previa mudanças não apenas biológicas e ambientais, mas também sociais e culturais. Ao mesmo tempo, ela apoiava a necessidade de pre- 
servar o espaço doméstico da influência masculina, único lugar no qual a mulher tinha algum tipo de poder e liberdade. E são dessas ideias que Sabato se apropria para fundamentar suas concepções a respeito da mulher e do movimento feminista. Seus ensaios "Hombre y mujer" e "La abstracción y la masculinidad", trazem longas citações de Lombroso, deixando de fora duas importantes informações sobre a autora: (1 $\left.1^{\underline{a}}\right)$ ela era partidária dos ideais positivistas, doutrina que Sabato combatia, mas que preferiu ignorar ao utilizá-la como exemplo, e ( $2^{\mathrm{a}}$ ) sendo formada em Letras e Medicina era autora de vários livros, dedicando-se a diversas atividades científicas nas áreas da psiquiatria e da antropologia, áreas nas quais é necessário o raciocínio lógico e interesse pela abstração. Mencioná-la fora do contexto no qual viveu, ignorando as diferentes forças que atuaram sobre ela, foi um risco que Sabato assumiu, sabendo, talvez, que poucos iriam contestá-lo, pois poucos conheciam (e hoje ainda é assim) a verdadeira natureza do trabalho desenvolvido pela italiana Gina Lombroso.

A questão da indiferença demonstrada pela mulher ao pensamento abstrato não se limita apenas ao campo da filosofia, atingindo também os campos das ciências naturais e da matemática. E nesse quesito, de acordo com Sabato, as mulheres também estão em enorme desvantagem. Quando se refere, por exemplo, àquela que foi a única mulher a ganhar dois Prêmios Nobel em duas diferentes disciplinas (química e física), ele assume uma postura condescendente, declarando: "Uma especialista é Madame Curie, que pacientemente isola um novo elemento químico; um homem de síntese é Einstein, que reúne em uma grande teoria milhares de pequenos fatos reunidos por especialistas. É a distância entre um pesquisador comum e um gênio" (SABAT0, 2006, p. 110-111, tradução nossa $)^{22}$. Sem cair no reducionismo, mas procurando acompanhar o raciocínio do autor, é como se ele dissesse que a genialidade, pelo menos no universo científico, só existe entre os homens, cabendo a mulher apenas um papel subalterno. Sabato convenientemente esquece, ou omite, as muitas mulheres que contribuíram para o desenvolvimento das ciências e da matemática: Gertrude Elion (1918-1999), Mária Telks (1900-1995), Grace Hopper (1906-1992), Maria Mayer (1906-1972), Cecilia PayneGaposchkin (1900-1979) e sua própria "chefe", nos tempos de Paris, Irène JuliotCurie (1897-1956).

Como fez quando tratou da filosofia, ele volta a mencionar seus "testemunhos valiosos", agora na figura da matemática russa Sofia Kowalevskaya. Conforme Sabato, Sofia foi empurrada para o trabalho científico porque estava apaixonada pelo matemático Weierstrass, ou seja, o que a levou a trabalhar em uma área tão abstrata como a matemática foi "o amor, uma coisa muito natural em uma mulher, e não pelo amor à própria ciência, uma coisa muito masculina" (SABATO, 2011a, p. 13, tradução nossa) ${ }^{23}$. 0 problema é que, da mesma maneira como aconteceu com Gina Lombroso, Sabato decide omitir informações importantes sobre a vida de Sofia.

O desejo de estudar matemática começou quando Sofia era ainda criança (11 anos), quando cobria as paredes de seu quarto com folhas de rascunho onde estavam anotados os cálculos diferenciais e integrais do mate-

22 "Un especialista es Madame Curie, que aísla pacientemente un nuevo elemento químico; un hombre de síntesis es Einstein, que reúne en una gran teoría miles de pequeños hechos aportados por especialistas. Es la distancia que hay entre un investigador común y un genio".

23 [...] el amor, cosa muy natural en una mujer, y no por amor a la ciencia misma, cosa muy de hombre". 
mático russo Mikhail Ostrogradski (18011862). Sabato também omite que impedida de estudar na sua terra natal sujeitou-se a um casamento de conveniência para poder cursar na Alemanha a universidade e que em 1874 defendeu sua tese de doutorado pela Universidade de Göttingen, sob a orientação do matemático Karl Weierstrass (seu suposto amante). Quando retorna à Rússia, Sofia, não conseguindo nenhum posto como professora de matemática, se vê obrigada a escrever críticas de teatro e artigos de ciência para um jornal em São Petesburgo ${ }^{24}$, mas após esse período difícil ela "conseguiu através de Weierstrass, uma posição de professora de matemática superior na Universidade de Estocolmo, onde lecionou de 1884 até sua morte em 1891" (FERNANDES, 2006, p. 45). E, por fim, Sabato esquece de dizer que as contribuições matemáticas de Sofia, centradas na teoria das equações diferenciais espaciais, permitiram-lhe demonstrar o que hoje é conhecido como Teorema de CauchyKowalevskaya. Essas informações colocam sob suspeita suas assertivas sobre as mulheres não terem interesse em explorar o pensamento puro, ou o mundo das abstrações, porque "só precisa do que tem por dentro: carregando o mundo e toda a humanidade em seu próprio seio (SABATO, 2011a, p. 92, tradução nossa $)^{25}$. Uma afirmação que pode até ter um certo conteúdo poético, mas que não corresponde à realidade.

No entanto, em 1953, Sabato estava decidido em defender essa posição, alegando que não foram as causas históricas as responsáveis pela ausência da mulher na his-

24 La mujer que empapeló su habitacion con teoremas. Disponível em: http://www.madrimasd. org/blogs/matematicas/2016/08/17/142255. Acesso em: 28 jul 2020.

25 “[... no necesita más que lo que tiene dentro: lleva el mundo y la humanidad entera en su propio seno". tória das criações, pois, “afinal, ninguém jamais proibiu as mulheres de especulação filosófica, nem da música ou do desenho" (SABATO, 2011a, p. 92, tradução nossa) ${ }^{26}$. Para Sabato, foram as condições biológicas e metafísicas que afastaram as mulheres da criação e das descobertas. Dessa forma, restavam a elas dedicarem-se às atividades que estão conectadas à sua essência profunda, ao seu corpo, à sua subjetividade como a "dança, a interpretação teatral, a interpretação musical, o romance de paixões (especialmente autobiográficos), as memórias, os diários; tudo aquilo que tende a imitação, a representação e a conservação" (SABATO, 2011a, p. 92, tradução nossa ${ }^{27}$.

Esse posicionamento, como foi mencionado, seria revisto em seu último livro España en los diarios de mi vejez (2004), quando admitiu que as mulheres talvez estivessem certas em se irritarem com suas opiniões machistas. 0 motivo para essa mudança de opinião se deve a ter conhecido a obra da espanhola María Zambrano (19041991), segundo ele, uma "gran filósofa", com a capacidade de buscar "uma racionalidade enraizada na vida, no vital" (SABATO, 2004, p. 125 , tradução nossa) ${ }^{28}$. E mesmo acrescentando que "ela é mais uma poeta ou uma poeta filósofa" (SABAT0, 2004, p. 125, tradução nossa) ${ }^{29}$, Sabato, finalmente, aceita a existência de mulheres interessadas em "filosofar". Um passo importante para um defensor da tese de que enquanto o homem

26 "[...] al fin de cuentas nadie prohibió nunca a la mujer la especulación filosófica, ni la música, ni el dibujo".

27 "[...] danza, la interpretación teatral, la interpretación musical, la novela de pasiones (sobre todo autobiográficas), las memorias, los diarios; todo aquello que tiende a la imitación, la representación y la conservación".

28 "[...] una racionalidad enraizada en la vida, en lo vital".

29 '[...] ella es más bien una poeta, o una poeta filósofa' 
estava sempre preocupado com o Universo, a mulher mesmo que o universo se desmorone terá como primeira preocupação o que ocorre dentro de sua casa.

\section{Considerações finais}

Nos ensaios sabatianos é perceptível a presença de uma estrutura constituída, basicamente, de três elementos: $\left(1^{\circ}\right.$ ) citação, pretexto ou afirmação precisa; ( $2^{\circ}$ ) exposição dialética do tema; e $\left(3^{\circ}\right.$ ) conclusões. Segundo Angela Dellepiane, essa estrutura poucas vezes variava, mas, seu objetivo - manter a atenção, levando o leitor pela mão por entre o tumulto de ideias - sempre se cumpria (DELLEPIANE, 1983). Do mesmo modo, a pequena extensão de muitos dos ensaios fazia com que neles se acumulassem recursos estilísticos com o objetivo de atingir um determinado nível estético, sem ter a pretensão de proporcionar soluções a problemas concretos. 0 trabalho realizado por Sabato, como ensaísta, exigia não apenas domínio de um certo conhecimento, mas, principalmente, maturidade intelectual, pois a liberdade de estilo, ritmo e expressão requerem sutileza e equilíbrio. Ademais, ao problematizar um conceito ou um tema seu propósito era incitar e inspirar o leitor à reflexão. Os ensaios sabatianos tornam-se, então, um veículo por meio do qual os pensamentos do autor são reunidos e organizados para que sejam levados ao leitor de maneira clara, concisa e interessante.

Nesse sentido, quando se analisa as afirmações de Sabato a respeito das mulheres pode-se seguir por dois caminhos: demonstrar os equívocos de sua interpretação, apenas citando nomes de mulheres que se dedicaram à filosofia, à ciência e à matemática ou tratar de entender que se está diante de um homem acostumado (e educado) a ver a mulher apenas como mãe e dona de casa. Qualquer que seja o caminho escolhido, é importante compreender o contexto no qual Sabato viveu, pensando não apenas na forma como foi criado por seus pais, mas, principalmente, na época em que suas obras foram escritas, em especial Heterodoxia, livro no qual aparecem, de forma mais contundente, suas ideias sobre a desigualdade dos sexos.

A partir dessa perspectiva é relevante lembrar que seus primeiros livros de ensaios foram publicados entre os anos de 1945 e $1953^{30}$, um período no qual as mulheres, de um modo geral, eram consideradas as "rainhas do lar" e, portanto, das quais se exigia o cumprimento das tarefas domésticas e que proporcionassem ao homem (o provedor) conforto e tranquilidade. Um período no qual conviviam duas éticas diferentes: (1) os homens procurando "raciocinar de maneira dedutiva, partindo de princípios gerais, quaisquer que sejam as consequências - como fazem em geral pessoas em situação de domínio" (FOUREZ, 1995, p. 246); e (2) as mulheres, compondo o grupo dos dominados, sendo mais atentas ao vivido, ao sofrimento, às contradições da existência. Por isso o exemplo de Gina Lombroso é "perfeito" já que ela, sendo uma defensora da preservação do espaço doméstico, livre da interferência masculina, aparentemente, fundamenta as ideias de Sabato sobre o lugar da mulher na sociedade. E se ele omite a personalidade complexa e as diversas atividades intelectuais (a maioria delas realizadas fora do lar) nas quais Lombroso esteve envolvida, atendo-se apenas ao que ela escreveu, ele apenas está utilizando um recurso comum entre os ensaístas, o de sugerir e incitar o leitor a refletir sobres suas posições, quer concorde ou discorde delas,

30 Uno y el universo (1945), Hombres y engranajens (1951) e Heterodoxia (1953). 
gerando um diálogo próprio do gênero ensaístico.

Podemos aplicar o mesmo raciocínio para as citações que envolvem a matemática russa Sofia Kowalevskaya. As posições do autor argentino atualmente seriam consideradas no mínimo polêmicas, mas, na época que as escreveu eram tidas como adequadas, tendo em vista sua formação e o ambiente no qual estava inserido. Além disso, é importante ressaltar que para Sabato essas declarações não tinham um conteúdo negativo ou pejorativo. 0 fato de as mulheres preocuparem-se com assuntos "concretos" e não estarem interessadas em abstrações é uma forma de elogio, pois, para ele, foi o aumento da abstração a causa do afastamento do homem do que considerava essencial. Para Sabato, os homens, ao contrário das mulheres, ao perseguirem as ideias puras e abstratas, acabaram se distanciando da vida, aproximando-se do frio universo dos objetos ideais, distantes dos problemas que afetavam o homem comum.

As discrepâncias percebidas no pensamento de Sabato refletem, em grande medi$\mathrm{da}$, as transformações pelas quais a sociedade de seu tempo passava quando o assunto era o papel desempenhado pela mulher. É interessante ressaltar que, apesar de sua formação intelectual privilegiada, a escritor argentino viveu boa parte de sua vida não só com a ética inculcada por um pai severo e uma mãe possesiva e controladora, mas com todo um contexto que marcou a época no qual seus primeiros livros foram publicados. Um cenário caracterizado pela ascensão do peronismo, cujos valores em relação às mulheres eram, no mínimo, contraditórios. Uma contradição que aparece na figura emblemática de Eva Perón (1919-1952) que se, por um lado, reivindicava que o "lugar das mulheres era no lar, junto a seus filhos e marido", por outro, "solicitava apoio político para difundir o peronismo, enviando-as pelo interior da Argentina e afastando-as de suas famílias" (VÁZQUEZ, 2009, p. 927). Sabato está escrevendo e publicando seus primeiros livros exatamente nesse período, e Eva Péron se parece muito a Gina Lombroso, mulheres que, apesar de suas fortes atuações na política e nas questões sociais (e científicas), refletiam a imagem da mulher-esposa, da mãe por excelência, submetida à autoridade do homem.

No entanto, é impossível ignorar que Sabato também viveu em um tempo no qual essa visão machista e paternalista da mulher já apresentava inúmeras fissuras. Como foi mencionado, em sua época já existiam muitas mulheres atuando em diversas áreas do conhecimento nas quais há a exigência de se desenvolver o pensamento abstrato. Por essa razão, pode-se pensar que muitas das contradições expressas por Sabato em seus ensaios estavam relacionadas a sua dificuldade pessoal de intuir e aceitar a heterogeneidade do tempo histórico que lhe coube viver.

De qualquer maneira, é difícil ficar impassível diante dos ensaios sabatianos. Ao escolher o gênero ensaístico Sabato estava se valendo de algumas de suas características mais marcantes: a transitoriedade, o esboço, o deslocamento e a errância. Além disso, a não preocupação que o ensaio, muitas vezes, tem com os recursos formais de uma pesquisa científica permite ao ensaísta certas imprecisões e desvios que a um artigo acadêmico é vetado. Desse modo, pode-se diferir e até se irritar com muitas de das posições do escritor argentino, porém é preciso reconhecer que, no cenário de seu tempo, ele foi uma força a ser considerada. Ernesto Sabato representou o tipo de ensaísta que precisou de seus ensaios para entender-se, 
pois neles ele dialoga consigo, ou com um leitor imaginário, para assim continuar refletindo.

\section{Referências}

CALLONI, Maria. Gina Lombroso: medicina, scienza e "anime di donne". Disponível em: http://unionefemminile.it/gina-lombroso-medicina-scienza-e-anime-di-donne/. Acesso em: 28 jul 2020.

CONSTENLA, Julia. Sabato, el hombre. La biografía definitiva. Buenos Aires: Sudamerica, 2011.

CORREA, María Angélica. Genio y figura de Ernesto Sábato. Buenos Aires: Editorial Universitaria de Buenos Aires, 1971.

DELLEPIANE, Angela B. Los ensayos de Sábato: intelecto y pasión. Cuadernos Hispanoamericanos, n. 391-393 (enero-marzo 1983). Madrid: Instituto de Cooperación Iberoamericana

FERNANDES, Maria da Conceição Vieira. A inserção e vivência da mulher na docência de matemática: uma questão de gênero. João Pessoa, 2006 (Dissertação de mestrado - UFPB).

FOUREZ, Gérard. A construção das ciências: introdução à filosofia e à ética das ciências. Tradução Luiz Paulo Rouanet. São Paulo: UNESP, 1995

HÜLSENDEGER, Margarete J. V. C. Os caminhos e descaminhos da ciência na obra de Ernesto Sabato. 2016. Tese (Doutorado em Teoria da Literatura) - Pontifícia Universidade Católica do Rio Grande do Sul, Porto Alegre, 2020.

LORENZ, Günter. Diálogo com a América Latina: panorama de uma literatura do futuro. Tradução de Rosemary Costhek Abílio e Fredy de
Souza Rodrigues. São Paulo: E.P.U., 1973.

MATAMORO, Blas. Lecturas americanas. Madrid: Ediciones de Cultura Hispánica, 1990

SÁBATO, Ernesto. Heterodoxia. Tradução Janer Cristaldo. São Paulo: Papirus, 1993.

SABATO, Ernesto. España en los diarios de mi vejez. Buenos Aires: Seix Barral, 2004.

SABATO, Ernesto. Uno y el universo. Buenos Aires: Seix Barral, 2006 (Edición especial para La Nación),

SABATO, Ernesto. Heterodoxia. Buenos Aires: Seix Barral, 2011a.

SABATO, Ernesto. Antes del fin. Buenos Aires: Seix Barral, 2011b (Edición especial para La Nación

VÁZQUEZ, María Laura Osta. Uma síntese da história das mulheres na Argentina. Estudos Feministas, Florianópolis, v. 17, n. 3, setembrodezembro, 2009.

WEINBERG, Liliana. Pensar el ensayo. México: Siglo XXI, 2007a.

WEINBERG, Liliana. El ensayo latino-americano entre la forma de la moral y la moral de la forma. Cuadernos del CILHA - v. 8; n. 9, 2007b.

WEINBERG, Liliana. 0 ensaio em diálogo. Da terra firme ao arquipélago relacional. Revista Remate de Males, v. 36, n. 2. Campinas: São Paulo (jul./dez.), 2017

WEININGER, Otto. Sex and character: an investigation of fundamental principles. Tradução de Ladislaus Lob. Indiana University Press, 2005.

Recebido em: 05/03/2021 Aprovado em: 22/05/2021 